ев М.К., Оразбаев А.М. Древняя культура Центрального Казахстана. Алма-Ата: Наука, 1966. С. 303-433.

3. Бейсенов А.З., Исмагулова А.О., К Китов Е.П., Китова А.О. Население Центрального Казахстана в I тыс. до н. э. Алматы: Институт археологии им. А.Х. Маргулана; Научно-исследовательский центр «Бегазы-Тасмола», 2015. 188 с.

4. Бейсенов А.З., Исмагулова А.О., Китов Е.П., Китова А.О. Население Центрального Казахстана в I тыс. до н. э. Алматы: Институт археологии им. А.Х. Маргулана; Научно-исследовательский центр «Бегазы-Тасмола», 2015. 188 с.

5. Китов Е.П., Бейсенов А.З. Черепа с трепанациями из курганов раннего железного века Сарыарки // Вестник Московского университета. Серия XXIII. Антропология. 2015. № 1. С. 37-48.

6. Бейсенов А.3. Сарыарка - колыбель степной цивилизации. Алматы: Научно-исследовательский центр «Бегазы-Тасмола», 2011. 32 с.

7. Бейсенов А.З. Поселения и могильники сакской эпохи Центрального Казахстана // Сакская культура Сарыарки в контексте изучения этносоциокультурных процессов Степной Евразии: сб. науч. статей, посв. памяти археолога К.А. Акишева. Алматы: Научно-исследовательский центр «Бегазы-Тасмола», 2015. C. 11-38.

8. Шевнина И.В., Сеитов А.М. Детское погребение раннего железного века из Тургая // Восхождение к вершинам археологии: сб. матер. междунар. научн. конф. «Древние и средневековые государства на территории Казахстана», посвящ. 90-летию со дня рождения К.А. Акишева. Алматы: Институт археологии им. А.Х. Маргулана, 2014. С. 273-280.

9. Бейсенов А.З., Джумабекова Г.С., Базарбаева Г.А. Изучение памятников тасмолинской культуры в Западной Сарыарке // Археология Западной Сибири и Алтая: опыт междисциплинарных исследований. Барнаул, 2015. С. 294-297.

10. Соенов В.И., Константинов Н.А., Трифанова С.А. Детские погребения могильника Степушка-2 // Известия Лаборатории древних технологий. 2015. № 3 (16). С. 9-27.

11. Соенов В.И., Константинов Н.А., Трифанова С.А. Особенности детского погребального обряда могильника Степушка-2 на Алтае (Предварительное сообщение) // Вестник ТомГУ. 2016. № 404. С. 143146.

12. Маргулан А.Х. К изучению памятников района р. Сары-Су и Улутау // Вестник АН КазССР. 1948. № 2 (35). С. 53-60.

13. Бейсенов А.З. Околокурганные жертвенники как разновидность памятников тасмолинской культуры // Вестник ТомГУ. 2015. № 4 (36). С. 96-104.

14. Берсенева Н.А. Социальная археология: возраст, гендер и статус в погребениях саргатской культуры. Екатеринбург: УрО РАН, 2011. 204 с.

Работа выполнена в при финансовой поддержке Комитета науки Министерства образования и науки РК, проект 2982/ГФ4 «Сарыарка в системе культур раннего железного века Степной Евразии».

\title{
CHILDREN BURIALS OF THE SAKA TIMES IN CENTRAL KAZAKHSTAN
}

(C) 2017

Beisenov Arman Ziyadenovich, candidate of historical sciences, head of Prehistoric Department

Bazarbaeva Galiya Appazovna, candidate of historical sciences, leading researcher of Prehistoric Department Duisenbay Daniyar Bolatbekovich, researcher of Prehistoric Department A.Kh. Margulan Institute of Archaeology (Alma-Ata, Republic of Kazakhstan)

Abstract. The materials on the children burials belonging to Tasmola culture in Central Kazakhstan were studied by M.K. Kadyrbaev and A.Z. Beisenov. As the analysis of available data shows there are only nine studied children burials of Tasmola culture. It is possible that some of the children graves, represented by small mounds, do not contain accompanying subjects and in the early period of research they were not mentioned on the pages of scientific publications and reports. New research shows that, along with small mounds, there are significant ones distinguished by their parameters and structure. Two of the nine constructions have diameters higher than $20 \mathrm{~m}$, one of them is 18 $\mathrm{m}$ and particularly notable is the kurgan 7 in the burial ground Akbeit studied in Karaganda Region. Its diameter is $21,5 \mathrm{~m}$, height $2,5 \mathrm{~m}$. A four or five year old child, probably a girl, was buried there. The child was buried in a rich dress, as evidenced by gold torque, worn around the neck, and two gold earrings, a bronze mirror, a bone case for cosmetics. Children burials of Tasmola culture as well as the adult burials indicate social strata of that society.

Keywords: children's burials; Central Kazakhstan; analysis of data; tasmolia culture; trepanation; Early Saka period; settings burial structures; social strata; status of child.

УДК 903/904: «638»: 365

\section{КРУГЛОЕ ЖИЛИЩЕ САКСКОЙ ЭПОХИ}

(C) 2017

Бейсенов Арман Зияденович, кандидат исторических наук, заведующий отделом первобытной археологии Институт археологии имени А.Х. Маргулана (2. Алма-Ата, Республика Казахстан)

Аннотация. На основе материалов раскопок поселения Туйетас рассматриваются особенности такой разновидности сакских жилищ, как круглоплановые дома. На территории Казахстана округлые каркасные жилища, наряду с прямоугольными, повсеместно бытовали в эпоху бронзы. Каркасные дома круглой планировки известны по материалам сакского времени Жетысу (поселение Бутакты-1). На поселении Туйетас, на раскопанном участке площадью 408 м² вскрыты остатки оснований одного округлого дома и двух пристроек хо- 
зяйственного назначения. Автор предполагает, что это был дом юртообразной формы с мощным каменным основанием (стеной) шириной не менее 1 м и деревянной верхней частью. Строение общим диаметром около 13 м имело внутри несколько помещений, широкие основания которых также выполнено из камня. Одно округлое помещение внутренним диаметром около 3-3,5 м располагалось в центре. Деревянные столбы от каркасных стен этого помещения одновременно поддерживали верхнюю конструкцию всего дома. Дома округлой планировки вскрыты на сакском поселении Сарыбуйрат, находящемся недалеко от поселения Туйетас. Такого типа строения зафиксированы в ряде других, еще не изученных поселений Центрального Казахстана. Изучение поселений сакского времени Центрального Казахстана находится на начальном этапе. Для всестороннего анализа многих аспектов, в том числе и относительно особенностей и типов жилищ, необходимо расширение источниковой базы.

Ключевые слова: поселения; жилища сакского времени; круглые дома; эпоха бронзы; диаметр каменного основания; деревянные столбы; верхняя конструкция; кровля; данные этнографии; тасмолинская культура.

В период 2000-2001 гг. автором была начата разработка вопросов поселений сакской эпохи Центрального Казахстана. В 2001 г. один из самых ранних раскопов на выявленных к тому времени немногочисленных объектов был заложен на поселении Туйетас, что в Каркаралинском районе Карагандинской области (рис. 1). Уже тогда было обращено внимание на небольшую округлую конструкцию, занимающую центральную часть внешнего, опять же округлого, сооружения, гораздо большего диаметра. Несмотря на скудость культурного слоя, малочисленность находок, вызвала интерес именно планировка жилого сооружения. Затем проводились исследования на поселениях Едирейской группы [1] и на других памятниках, причем на поселении Сарыбуйрат, что недалеко от Туйетаса, были выявлены также округлые строения жилищного назначения [2]. На едирейских поселениях, как и на поселении Тагыбайбулак, для жилищных строений оказались характерными также подпрямоугольные, относительно вытянутые формы. Таким образом, в последние годы, после 15-летнего наблюдения и работы с материалом, выяснилось, что можно говорить на данном этапе исследований о двух типах жилищных строений сакской эпохи Центрального Казахстана. Вместе с тем, нельзя утверждать, что подпрямоугольные (вытянутых пропорций) и круглоплановые (округленных форм) дома следует считать единственными и, главное, разработанными, «типами» сакских жилищ для данного региона. Памятуя о малоисследованности вопроса, а также и в рамках определенного понимания самой природы изучаемого явления в виде культуры древних, скотоводческих общин аридной зоны с повышенным стремлением к адаптации условиям конкретной экологической ниши, не следует делать окончательные выводы. На многих памятниках, неизученных раскопками, замечены многосоставные строения. Высказано предположение рассматривать открытые в Казахском мелкосопочнике к настоящему времени многочисленные поселенческие объекты с каменными строениями в качестве зимников (поселения-зимовки), что, разумеется, ставит вопрос необходимости поиска летних стойбищ [3].

В недавнем сообщении автора были вкратце рассмотрены некоторые особенности упомянутых сакских домов попрямоугольных форм. Одним из важных наблюдений, на взгляд автора, явилось предположение, согласно которому относительно узкие, вытянутые пропорции строений диктовались необходимостью решения вопроса кровли. В этом случае, небольшой пролет, к чему стремились жители, наиболее надежно обеспечивал устойчивую плоскую кровлю с толстым земляным утеплителем. В конечном счете цель заключалась в экономии тепла, в виду чего, высокие и более просторные дома, аналогичные жилищам эпохи бронзы, оказались невостребованными в новых условиях [3].

Описания и реконструкции домов эпохи бронзы, сделанные казахскими археологами А.Х. Маргуланом [4] и А.М. Оразбаевым [5], а также и рядом других ученых, занимавшихся проблемами изучения культур бронзы Урала, Западной Сибири, достаточно близки друг к другу. Это каркасные постройки с усеченно-пирамидальной крышей (рис. $2 ; 3,1$ ), в верхней конструкции которых важную роль играет прямоугольная рама, поддерживаемая вертикальными столбами. А.М. Оразбаевым была предложена также реконструкция круглопланового жилища юртообразного типа [6, рис.9]. Известны для эпохи бронзы и легкие конусовидные шалаши из жердей. В частности, реконструкция такого жилища была сделана П.А. Дмитриевым [7] по материалам Зауралья (рис. 3, 2).

На казахстанском материале мнение о круглоплановых домах сакского времени высказано не так давно А.А. Горячевым. На поселении Бутакты-1 на юго-восточной окраине г. Алматы им выявлены остатки круглых жилищ, каркасные стены которых состояли из жердей, обмазанных глиной [8, с. 91-93]. Материал относится к позднесакскому периоду (IVIII вв. до н.э.).

На поселении Туйетас на раскопанном участке площадью $408 \mathrm{~m}^{2}$. выявлены остатки каменных конструкций от основного округлого строения и двух пристроек, находящихся с восточной и южной сторон (см.: [9]). Основное сооружение А (рис. 4) и две пристройки Б, В сохранились в разной степени. Сохранность всех указанных конструкций плохая вследствие как естественных развалов стен, так и выборки камня местным населением. Особенно пострадали стены пристроек, расположенных с восточной и южной сторон основного сооружения. Как и в других случаях, поселение Туйетас расположено у самого подножия высокой и скалистой возвышенности, с южной ее стороны. Основное сооружение почти примыкает к горной гряде, поэтому, подход и подъезд к нему явно затруднен, тогда как обе пристройки более открыты и удобны для разборки и дальнейшей погрузки камня на транспорт. В пристройках выявлены всего семь ям, часть которых, имеющих длину не менее 0,6 м, можно, по-видимому, считать хозяйственными. Золистые участки фиксировались в обеих пристройках, в особенности, содержание золы было более интенсивным в южной части пристройки Б и южном, юго-восточном сектоpax пристройки В. Пристройка Б, по-видимому, имела форму, близкую к овалу и длину не менее 10 м. Размеры и форма пристройки В не поддаются определению ввиду плохой сохранности. Обе пристрой- 
ки, скорее всего, выполняли функцию хозяйственных помещений. Пристройка В, в дополнение к этому, служила также и в качестве сеней, так как через нее осуществлялся проход к основному жилому сооружению А. Основное строение представлено мощными, широкими развалами каменных стен. Выборка камней поздними строителями осуществлялась более интенсивно в южной половине строения, особенно в районе входа, который достаточно четко читается благодаря разрыву, обращенному на юг. Форма строения округлая, диаметр по внешней кромке развалов - около 13 м. Ширина развала от стен - от 1 до 2 м. Внутри выделены несколько условных помещений по каменным основаниям, которые сохранились гораздо хуже, чем стены основного строения. Помещение I полукольцом с севера и запада охватывает центральную часть, которую занимает помещение II. C восточной и юго-восточной сторон от последнего расположены небольшие «отсеки» III и IV. В северозападном «углу» помещения I на материке выявлено большое пятно с сильным зольным содержанием, что трактуется как место открытого очага. Еще одно широкое пятно золы отмечено прямо у входа, здесь, повидимому, также горел огонь. Остальные все три помещения характеризуются отсутствием золы. Внутри основного сооружения выявлены восемь небольших ямок от столбов, которые располагались вдоль восточной внешней стены. Центральную часть строения занимает округлое помещение II диаметром развала около 5 м по внешней кромке.

На современном этапе изучения особенностей поселенческих объектов востока Центрального Казахстана автор данное помещение II рассматривает в качестве особого, планиграфически специально выделенного элемента круглоплановых жилищ сакской эпохи. Это мнение строится на том положении, что автор гипотетически допускает совмещение в этом элементе двух функций - помещения, скорее, жилого, и опоры для верхних конструкций. Здесь по контуру рассматриваемого центрального сооружения, возможно, стояли деревянные опоры, поддерживающие верхнюю раму от кровли. Раскопки не выявили четких ямок от этих столбов.

На основании мнений Б.А. Шрамко по материалам жилищ Бельского городища и ряда других специалистов, а также этнографических данных, автор полагает, что одной особенностью жилищ раннего железного века Евразии являлось отсутствие или немногочисленность столбовых ям. Опорные стойки могли быть вбиты или установлены на незначительную глубину, поставлены на землю без всяких углублений, обложены камнями, вставлены в отверстия лежащей на полу деревянной плахи т.п. (подробнее см.: [3]). Обшитые деревом (жерди, прутья) стойки составляли каркасную стену помещения, внутренний диаметр которого составлял около 33,5 м. Если внутренний диаметр всего большого сооружения равнялся 10 м, при ширине наружной основной стены в 1-1,5 м, то основные перекрываемые пролеты - центр и периферия - могли иметь длину около 3-3,5 м. Для регионов с холодным климатом кровля была связана с утеплителем, в том числе земляным. Была прямая связь между длиной пролета и тяжестью кровли, составляющей ту или иную нагрузку на деревянные балки. Судя по современным расчетам, вышеуказанная предполагаемая длина пролета для данного жилища могла обеспечить наличие кровли с достаточно тяжелым утеплителем (о результатах проведенных западносибирскими археологами экспериментов см.: [10; 3]). В предлагаемой автором условной реконструкции круглопланового жилища поселения Туйетас (рис. 5) центральное сооружение показано в виде правильного круга, стойки от которого поддерживают вверху округлую раму. Это чистая условность. Рама могла быть прямоугольной, квадратной, многоугольной и поддерживаться четырьмя, пятью столбами и т.п. Таким образом, жерди или бревна перекрытия покоились на раме и каменной стене, более низкой, чем центральная часть строения. Вышеуказанные небольшие ямки вдоль восточной внешней стены, по-видимому, остались от стоек, дополнительно поддерживавших бревна перекрытия. Округлая форма строения и наличие верхней рамы создает тип жилища с усеченно-пирамидальной или усеченно-конической крышей, восходящего к жилищам эпохи бронзы. Для округлых жилищ вторым типом перекрытия может быть та же плоская кровля, рассмотренная на примере вышеуказанных едирейских поселений. Но для круглоплановых жилищ с плоским перекрытием отпадает необходимость выделения в центре специального элемента в виде помещения округлой формы, здесь для устойчивости плоской кровли над относительно большой площадью могли быть размещены перегородки любой планировки. Реконструкцию следует считать предварительной, в качестве одного из перспективных направлений. Для едирейских плоских домов высота была предположена на уровне около 2 м. В шатровом доме условно можно допустить наличие более приподнятой крыши, к примеру, высотой в центре около 2,5 м. Эти цифры на данном этапе исследований никак не могут быть даже относительно точными.

Предположение о шатровом типе перекрытия круглоплановых домов сакского времени востока Центрального Казахстана допускает возможность существования аналогичных легких жилищ, используемых в теплое время года. Юртообразным сооружением можно считать и рассмотренное жилище на поселение Туйетас. Если высказанное предположение подтвердится на новых материалах, то окажется допустимым бытование в сакскую эпоху легких жилищ, максимально приближенных к тюркской юрте.

Юрта [11-13] является хорошо известным типом жилища степного населения. В ряде исторических дисциплин, в том числе археологии, рассматривались нюансы по поводу того, что считать юртой, юртообразными сооружениями [14; 15], высказывались мнения по поводу происхождения самой юрты, ее особенностей, и т.п. Развертка и обсуждение всех аспектов этой проблематики не входят в задачу настоящего сообщения. Краткого рассмотрения требует один вопрос, связанный, прежде всего, с археологическим видением сути происхождения тюркской юрты. Крупнейший специалист по археологии бронзы степной Евразии Е.Е. Кузьмина наиболее четко обозначила этот рубеж.

Как кажется, мнения о происхождении юрты условно можно разделить на две группы. Первая представлена высказываниями не археологов, здесь много представителей разных отраслей науки, в том числе культурологов, искусствоведов, дизайнеров и т.П. Юрта связывается с любым сооружением древности, имеющим коническую форму или вообще за- 
остренный верх. Вторая группа исследователей это археологи или другие специалисты, применяющие, на основе существующей методики, археологический материал в своих суждениях. Е.Е. Кузьмина и В.А. Лившиц в 1987 г. впервые обратили внимание на то, что юрта является двухчастной конструкцией и по этой причине она не может быть сопоставлена с жилищами типа чума или шалаша [16]. Юрта в конструктивном отношении имеет шанырак (шанграк, шангарак, чангырак), который должен быть сопоставлен с деревянной рамой в верхней части жилищ эпохи бронзы. Е.Е. Кузьмина, таким образом, древнейший прототип юрты не только видела в жилищах эпохи бронзы, как многие продолжают обобщенно высказываться и сейчас без конкретных доказательств, не видя и не выделяя самый нужный механизм в логическом построении, но и показала почему это так. Еще ранее, в 1975 г. Л.Г. Нечаева, кажется, впервые, сравнила шанырак и верхнюю раму в конструкции древнего жилища. Речь шла об изображении шатра на стене склепа Анфестерия в Керчи, датируемом рубежом н.э., на котором она усмотрела наличие указанного элемента. Л.Г. Нечаева, называя данный шатер «юртой знатного кочевника», отметила, что деревянный каркас прислонен «вверху к небольшой квадратной раме, которая выполняла такие же функции, как чангарык-харочи-тон (деревянный круг, на который опираются шесты кровли), или, точнее, их предшественники, применяемые в круглой, преимущественно решетчатой юрте» [17, с. 14]. Этот момент специально подметили в своей работе Е.Е. Кузьмина и В.А. Лившиц: «Эту раму Л.Г. Нечаева справедливо считает прототипом шанграка юрты, генезис же ее можно возвести к светодымовым рамам срубно-андроновских домов с пирамидально-ступеньчатым сводом» [16, с. 249]. Кстати, в этой же работе авторы особо подчеркивают заслугу А.М. Оразбаева в исследовании вопроса происхождения юрты: «А.М. Оразбаев первым детально сопоставил конструкцию легких и круглых жилищ, исследованных им на поселении Чаглинка в Северном Казахстане, с конструкцией современного казахского жилища шошала и с кочевой юртой и пришел к заключению, что прототипом современной юрты... можно считать жилые строения племен поздней бронзы» [16, с. 245].

С.И. Вайнштейн, обсуждая то же самое изображение жилища из керченского склепа, не был согласен с мнением Л.Г. Нечаевой по поводу сравнения рамы с шаныраком юрты. Исследователь, по-видимому, ставил под сомненье наличие самой рамы и выразил мысль о том, что функцию скрепления выполняли простые палки-обвязки [15]. В работе Е.Е. Кузьминой и В.А. Лившица отрицается прямая связь гуннского жилища с юртой, на основании того, что «это (чум и гуннский шалаш - А.Б.) жилища одночастные по вертикали, тогда как юрта, подобно скифскому шатру, жилище двухчастное, имеющее вертикальные стены и выделенную крышу» [16, c. 250]. Образом «скифского шатра» здесь служит, как у многих других исследователей, указанное изображение из Керченского склепа. Следует отметить, что С.И. Вайнштейн совсем по-другому рисует облик «гуннского шалаша». Согласно его описанию, гуннскому жилищу присущ куполообразный верх, который выше переходит в невысокую шейку для дымохода, основание шейки скрепляется деревянным кругом [15]. В таком описании уже появляется элемент, функционально тождественный раме и шаныраку. В этом случае гуннское жилище перестает быть одночастным и приближается к конструкции юрты. В задачу настоящего сообщения не входило выяснение современной ситуации по характеристике гуннского жилища, но согласно приведенному мнению С.И. Вайнштейна, оно может оказаться ближайшим по хронологии предшественником тюркской юрты.

Таким образом, на жилище поселения Туйетас (VII-V вв. до н.э.) предполагается наличие невысокой шатровой крыши, возможно, близкой к усеченно-коническим типам. Могли бытовать облегченные, летние аналоги таких жилищ в виде двухчастного строения, близкого по своей конструкции юрте.

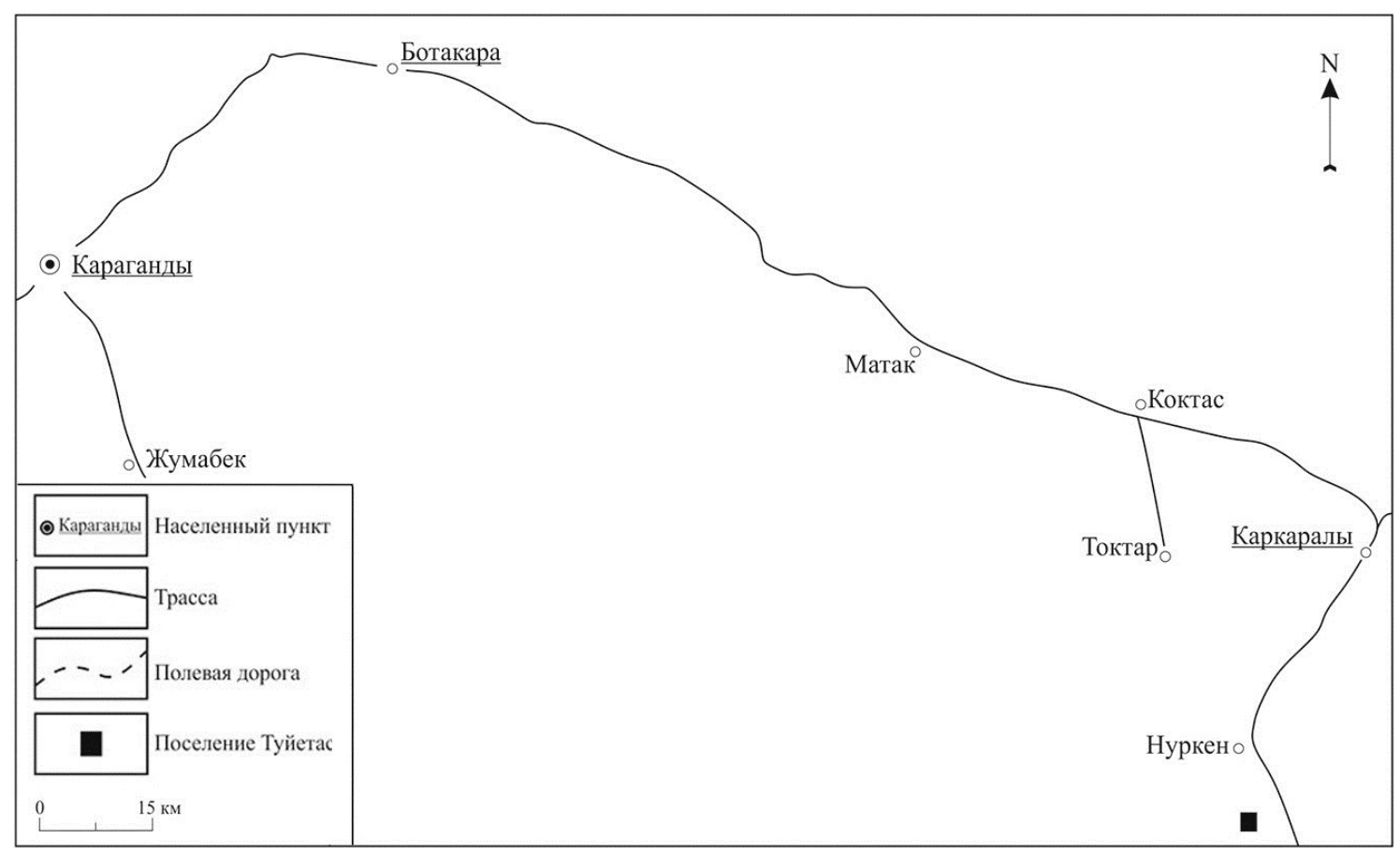

Рисунок 1 - Карта расположения поселения Туйетас 
Бейсенов А.3.
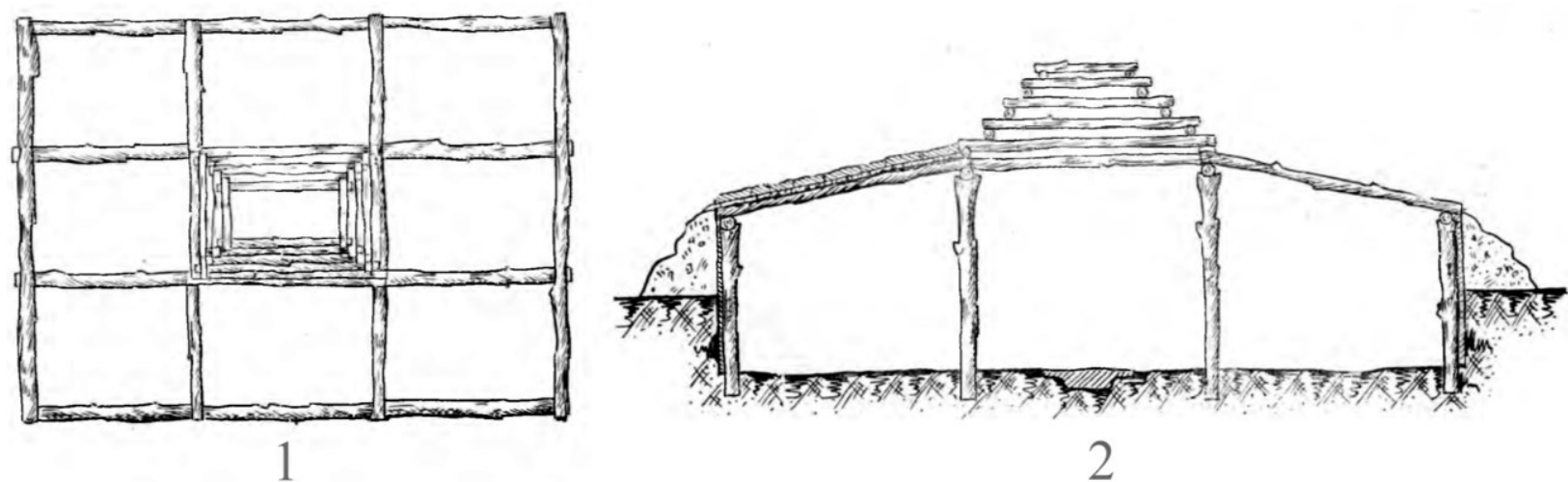

Рисунок 2 - Жилище эпохи бронзы. Реконструкция А.Х. Маргулана. 1 - вид сверху, 2 - разрез (по [4])
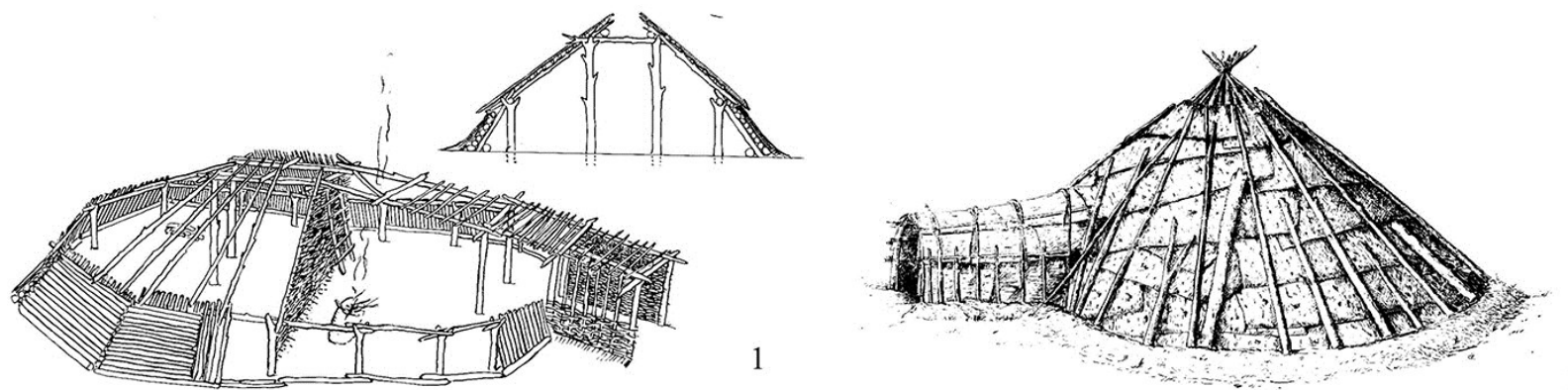

Рисунок 3 - Жилища эпохи бронзы. 1 - жилище с шатровой крышей, реконструкция А.М. Оразбаева (по [5]). 2 - шалаш, реконструкция П.А. Дмитриева (по [7])

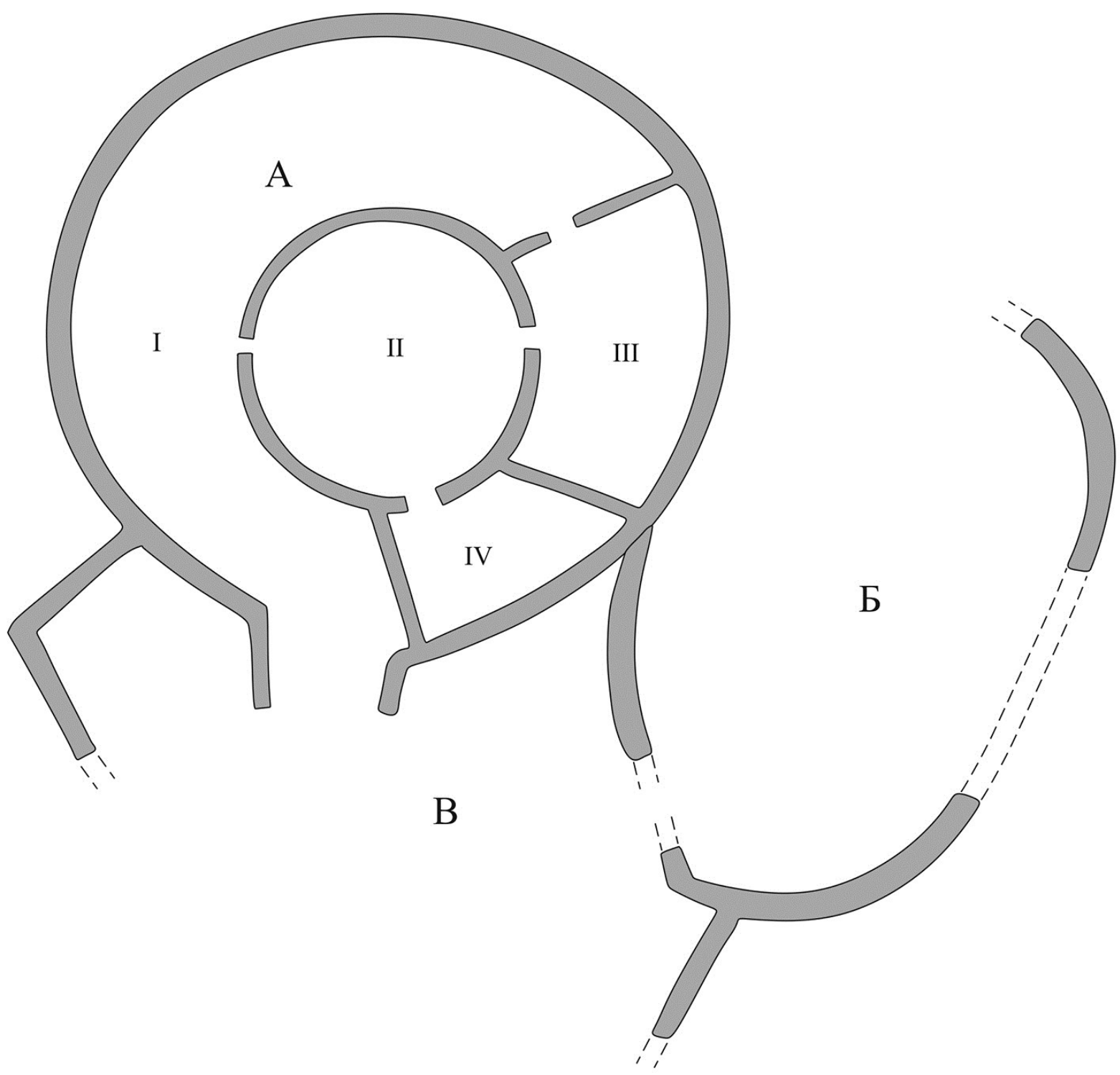

Рисунок 4 - Схематический план жилища на поселении Туйетас 


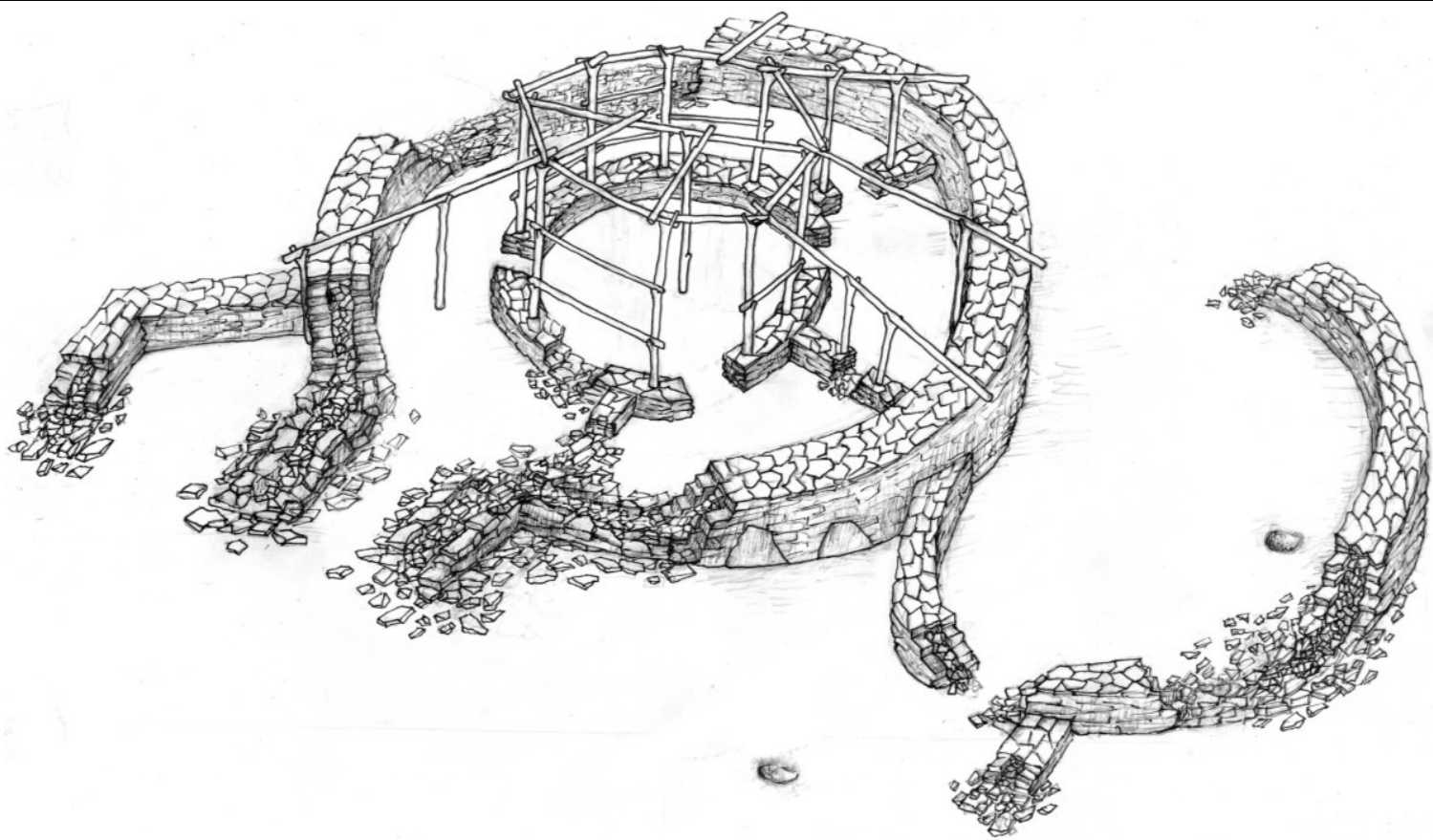

Рисунок 5 - Жилище поселения Түйетас. Реконструкция А.З. Бейсенова

\section{СПИСОК ЛИТЕРАТУРЫ:}

1. Бейсенов А.З. Раннесакские поселения близ горы Едирей в Центральном Казахстане // Известия Самарского научного центра. 2016. Т. 18, № 3. C. $146-152$.

2. Бейсенов А.3., Ломан В.Г. Древние поселения Центрального Казахстана. Алматы: Институт археологии им. А.Х. Маргулана, 2009, 264 с.

3. Бейсенов А.3. Жилище сакской эпохи // Вестник Томского государственного университета. 2017. № 45. C. 72-81.

4. Маргулан А.Х., Басенов Т.К., Мендикулов М.М. Архитектура Казахстана. Алма-Ата: Наука, 1959. $172 \mathrm{c}$.

5. Маргулан А.Х., Акишев К.А., Кадырбаев М.К., Оразбаев А.М. Древняя культура Центрального Казахстана. Алма-Ата: Наука, 1966. 433 с.

6. Оразбаев А.М. Поселение Чаглинка (Шагалы). Некоторые формы и типы жилищ // По следам древних культур Казахстана. Алма-Ата, 1970. С. 67-83.

7. Дмитриев П.А. Культура населения Среднего Зауралья в эпоху бронзы // Материалы и исследования по археологии Урала и Приуралья. М.: АН CCCP, 1951. T. 2. C. 7-27.

8. Горячев А.А., Егорова Т.А. Поселение раннего железного века в ущелье Бутаковка (юго-восточная окраина г. Алматы) // Сакская культура Сарыарки в контексте изучения этносоциокультурных процессов Степной Евразии. Алматы, 2015. С. 90-99.

9. Ахияров И.К., Бейсенов А.З.Поселение сакской эпохи Туйетас в Центральном Казахстане // Акту- альные проблемы археологии Евразии. Алматы, 2016. C. 237-244.

10. Берлина С.В., Филисюк В.Г. К проблеме реконструкции кровли древних полуземляночных жилищ (по материалам саргатской культуры) // Вестник археологии, антропологии и этнографии. 2005. № 5. C. 67-73.

11. Маргулан А.Х. Казахская юрта и ее убранство. Отдельный оттиск. М., 1964. 14 с.

12. Муканов М.С. Казахская юрта. Алма-Ата: Онер, 1986. 200 c.

13. Востров В.В., Захарова И.В. Казахское народное жилище. Алма-Ата: Наука, 1989. 181 с.

14. Флёров В.С. Раннесредневековые юртообразные жилища Восточной Европы. М.: Институт археологии РАН, 1996. 100 с.

15. Вайнштейн С.И. Проблемы истории жилища степных кочевников Евразии // Советская этнография. 1976. № 4. С. 42-62.

16. Кузьмина Е.Е., Лившиц В.А. Еще раз о происхождении юрты // Прошлое Средней Азии. Душанбе, 1987. C. 243-250.

17. Нечаева Л.Г. О жилище кочевников юга Восточной Европы в железном веке (І тыс. до н.э. первая половина II тыс. н.э.) // Древние жилища народов Восточной Европы. М., 1975. С. 7-49.

Работа выполнена в при финансовой поддержке Комитета науки Министерства образования и науки РК, проект 4370/ГФ4 «Исследование раннесакских поселений Центрального Казахстана».

\section{ROUND DWELLINGS OF THE SAKA EPOCH}

(C) 2017

Beisenov Arman Ziyadenovich, candidate of historical sciences, head of Prehistoric Department A.Kh. Margulan Institute of Archaeology (Alma-Ata, Republic of Kazakhstan)

Abstract. Based on the excavation materials from the settlement Tuyetas studied by the author on the territory of Karaganda Region, the characteristics of such a type of Saka dwellings as round houses are considered. According to archaeological research, on the territory of Kazakhstan rounded frame dwellings, along with rectangular, were commonly widespread in the Bronze Age. The frame house with round plan is known from the materials of Saka time 
Zhetysu (settlement Butakty-1). On the settlement Tuyetas on the excavated area of 408 square meters the remains of foundations of round houses and two annexes were revealed. The author suggests that it was the house of the yurtshaped form with a powerful stone base with a minimum width of $1 \mathrm{~m}$ and a wooden top. The construction with the overall diameter of about $13 \mathrm{~m}$ had several rooms, extensive grounds which were also made of stone. One round room with a diameter of about 3-3,5 $\mathrm{m}$ was in the centre. Wooden poles on the frame walls of the room at the same time supported the upper structure of the house. Houses of round plan were opened at the Saka settlement Sarybuyrat, located near the settlement of Tuyetas. This type of construction is recorded in a number of other not yet studied settlements in Central Kazakhstan. The study of Saka settlements in Central Kazakhstan is at the initial stage. The source base should be broadened for a comprehensive analysis of many aspects, including features and types of dwellings.

Keywords: settlements; Saka dwellings; round house; Bronze Age; diameter of stone base; wooden poles; upper structure; roofing; materials of ethnography; tasmola culture.

УДК 94(470.66)Т-50

\section{РОССИЙСКО-ЧЕЧЕНСКИЕ ВЗАИМООТНОШЕНИЯ В ХVI-XVII ВЕКАХ}

(C) 2017

Товсултанов Рустам Алхазурович, кандидат исторических наук, доцент кафедры новой и новейшей истории

Чеченский государственный университет (2. Грозный, Российская Федераџия)

Галимова Лилия Надиповна, доктор исторических наук,

профессор кафедры гуманитарных и социальных дисциплин

Ульяновский институт гражданской авиаџии имени главного маршала авиащии Б.П. Бугаева

(2. Ульяновск, Российская Федеращия)

Оздамирова Элиза Мусатовна, старший преподаватель кафедры новой и новейшей истории

Чеченский государственный университет (г. Грозный, Российская Федерация)

Аннотащия. В настоящей статье исследуются русско-чеченские взаимоотношения в XVI-XVII веках. Отмечается, что Кавказ попал в сферу российской внешней политики на этапе образования Русского централизованного государства. С присоединением Астраханского ханства Россия вышла к кавказским границам, и с этого времени кавказское направление займет ведущее место в восточной политике царского правительства. Кавказ в XVI в. являлся объектом острейшей борьбы между двумя самыми сильными державами тогдашнего Среднего Востока - Османской империей и Сефевидским Ираном - и одновременно плацдармом, откуда шла постоянная угроза для южных окраин России со стороны этих государств и Крымского ханства (вассала Порты). Укрепление России на кавказских землях могло стать наиболее надежным средством в обеспечении безопасности юга России. Так что в XVII и в XVII вв. Северный Кавказ представлял для России интерес в основном военно-стратегический, или, говоря современным языком, геополитический. Сама Чечня попала под влияние России в 1567 году, когда был заложен первый русский военизированный Терский город на Северном Кавказе. Для народов Северного Кавказа и Чечни появление русской крепости на их землях имело большое политическое значение.

Таким образом, в силу сложившейся ситуации для России жизненно необходимо было укрепиться на Северном Кавказе, так как на этой территории мог закрепиться враг (Иран и Турция), что было небезопасно для южных ее границ. Именно в этот период (конец XVI в.) устанавливаются тесные военно-политические связи московского правительства с чеченцами. Интерес московского правительства к Чечне объяснялся, прежде всего, ее географическим положением - непосредственным соседством с терскими городками и тем, что по ее территории проходили наиболее удобные пути сообщения с Грузией.

Взаимоотношения Чечни и России в конце XVI - первой половине XVII в. - почти идеальная для тех условий и того времени «модель» мирного сближения чеченцев с московским государством. Российские власти не вмешивались во внутренние дела чеченских обществ, не навязывали им свои порядки и законы, довольствуясь выдачей аманатов, выплатой ясака и, в случае необходимости, временной воинской службой. Bсе это привело к тому, что в XVII в. происходит установление союзнических отношений обществ Чечни с Россией. Однако в самом конце XVII в. русско-кавказские связи значительно ослабевают.

Ключевые слова: Кавказ; российская внешняя политика; Россия; Московское царство; восточная политика; царское правительство; Северный Кавказ; Чечня; Терек; Сунжа; Дагестан; крепость; Москва; северокавказские народы; российское государство; Средняя Азия; Закавказье; Турция; Иран; южные границы; московское правительство; чеченцы; русско-северокавказские отношения; политическая ситуация; посольство; посол; подданство; российско-чеченский договор; присяга; политический курс; взаимоотношения.

Кавказ попал в сферу российской внешней политики на этапе образования Русского централизованного государства. Борьба России с татарскими ханствами в Поволжье совпала с усилением стремлений Персии и Османской империи (Турции) завоевать Кавказ. Осуществление этих планов не только ослабляло позиции России на Кавказе (экономические и политические связи с которым укрепились еще с конца XV века), но и создавало плацдарм для дальнейшего продвижения названных государств в глубь России [1, с. 9]. Таким образом, с 1514 г. «Кавказ стал ареной ожесточенной борьбы между Ираном и Турцией ... Она продолжалась вплоть до подписания между ними в 1555 г. мирного договора, по которому западная часть Грузии и Армении отошла к Турции, а остальные районы Грузии и Армении - к 